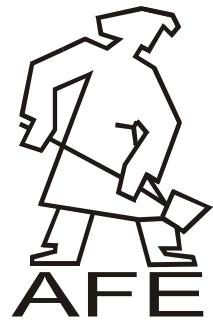

ARCHIVES

of

F O U NRY ENG INEERING

DOI: $10.2478 / \mathrm{v} 10266-012-0085-\mathrm{y}$
ISSN (2299-2944)

Volume 12

Issue $3 / 2012$

Published quarterly as the organ of the Foundry Commission of the Polish Academy of Sciences

\title{
Applying RP-FDM Technology to Produce Prototype Castings Using the Investment Casting Method
}

\author{
M. Macků *, M. Horáček \\ Faculty of Mechanical Engineering -Foundry Department, Brno University of Technology, \\ Technická 2896/2, 61669 Brno, Czech Republic \\ *Corresponding author. E-mail address: martin.macku@email.cz
}

Received 16.04.2012; accepted in revised form 02.07.2012

\begin{abstract}
The research focused on the production of prototype castings, which is mapped out starting from the drawing documentation up to the production of the casting itself. The FDM method was applied for the production of the 3D pattern. Its main objective was to find out what dimensional changes happened during individual production stages, starting from the 3D pattern printing through a silicon mould production, wax patterns casting, making shells, melting out wax from shells and drying, up to the production of the final casting itself. Five measurements of determined dimensions were made during the production, which were processed and evaluated mathematically. A determination of shrinkage and a proposal of measures to maintain the dimensional stability of the final casting so as to meet requirements specified by a customer were the results.
\end{abstract}

Key words: Rapid prototyping, 3D pattern, ABS pattern, Silicon mould, Casting, Dimensional stability

\section{Introduction}

The verification of possibilities of applying a suitable RP method enabling a foundry to offer fast prototype castings to potential as well as existing customers was the main objective of this part of the research. The Fimes foundry selected a specific part for this purpose, at which the suitability of the RP technology was verified. A pattern from the ABS material was made in the first stage, which was used to make a master silicon mould, with the help of which, wax patterns were then produced. The castings themselves were made using the technology of investment casting to a shell mould in the FIMES Company. It is possible to compare patterns made in this way with the classical conventional technology of using a master mould.

Comparing dimensional changes in individual experiment phases (i.e. following dimensions starting from the drawing of the part through an ABS pattern itself, wax patterns up to final castings) was another partial task of this research activity.
Dimensional changes were measured at places critical (from the point of dimensions) for the given part. An analysis of changes in given production stages was then made based on dimensional changes. Actual changes of dimensions were recorded from these pieces of knowledge starting from the drawing of the part up to the final casting, according to which drawing values were adjusted so that the final casting conformed to dimensions required by the customer.

It was followed, moreover, how many castings of this geometric configuration satisfying dimensional requirements of a customer can be produced with the help of the RP technology using silicon moulds.

\section{Production procedure}

The "Inlet Tank" of FIMES a.s. company featured in Fig. 1 and Fig. 2 was selected for the work. The technological procedure of its 
production is described starting from the drawing documentation up to the physical casting. It is a part used to deliver the coolant to the radiator in the cooling system of a motor truck.

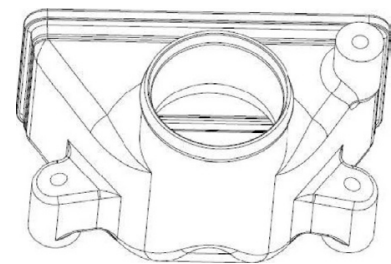

Fig. 1. Selected 3D part

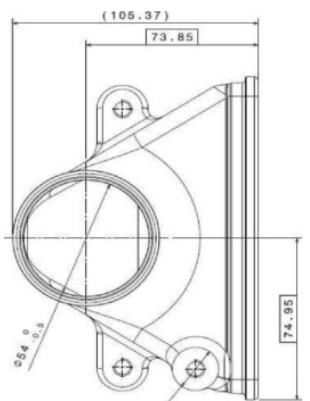

Fig. 2. Technical drawing of the part

\section{Technological procedure of the production:}

A. Preparation of data for the 3D print

B. Printing the ABS pattern using the FDM printing machine

C. ABS pattern preparation for the silicon mould production

D. Silicon mould production

E. Casting wax patterns to the silicon mould

F. Castings production using the investment casting technology

\section{A. Preparation of data for the 3D printing}

The part was modelled in the 3D SolidWorks program, where the pattern was converted do the STL format. The STL format is the basic input data for the most equipment of Rapid Prototyping including the FDM equipment. The STL format divides the 3D pattern into a large number of small, triangle shaped areas, which cover the entire surface of the pattern. The more complex pattern and the higher precision of the surface required, the higher the number of smaller triangles is used. Errors of connections of the individual points may occur at converting the $3 \mathrm{D}$ pattern to the STL format, which the device would detect then as a free part and this part would not be printed. That is why a correctness of the conversion to the STL format must be checked and these possible errors must be corrected.

\section{B. ABS pattern printing using the FDM (Fused Deposition Modelling) equipment}

The FDM Dimension uPrint printing machine was used to print the pattern. The CatalystEX program is the control software for the $3 \mathrm{D}$ data editing. The program serves as an intermediary among the generated 3D data in the STL format and the printing machine itself. The program can be installed on any computer, with the help of which the printing machine is then controlled. The computer communicates with the printing machine using an IP address, so that it need not be located at it directly. All data editing and the communication with the printing machine is done straight on the PC, the print initiation itself only must be done manually on the printing machine.

After setting all parameters necessary for the correct printing of the $3 \mathrm{D}$ pattern, a suitable printing orientation has to be set. Then the program displays how the pattern will look like after printing, including supports needed for the stability of the printed part (grey colour is used for the pattern itself, red for supports).

The program also announces what quantity of material will be used for the construction of the pattern itself and for the construction of supports. It gives also the total length of printing the part with supports. After the final check of the data setting, the data are sent to the printing machine and printed.

\section{Print principle of the printing machine}

The printing machine operates quite automatically without the necessity of control. It is watched by a program, which records all pieces of information from the printing machine. The printing machine works with a program on a remote computer. After sending the print statement, the printing machine is activated manually on its display.

A steady temperature around $73-75^{\circ} \mathrm{C}$ is maintained by two hot-air fans in the working chamber. The material in the print head is heated close below the melting temperature, which is about $293^{\circ} \mathrm{C}$. The print head makes a base-plate from the auxiliary material at first, on which the pattern itself is made. The print head makes individual layers subsequently. At making a layer, the auxiliary material (of black colour) is laid at first; the print head replaces the auxiliary material by the pattern material (of white colour) afterwards automatically and continues in printing this layer. Each material is stored in coils in separate supply tanks (Fig. 3).

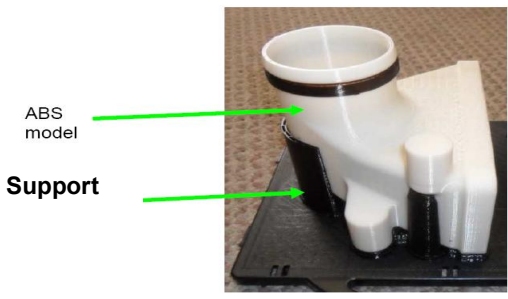

Fig. 3. Printed part with supports (in black colour) located on the base-plate

\section{Preparation of ABS pattern for the silicon mould production}

After printing, supports were removed mechanically (using screwdrivers, scrapers, and tongs), and placed in the ultrasonic vibration scrubber (with sodium hydroxide and water of temperature between $45^{\circ}-60^{\circ} \mathrm{C}$ as a solvent). The pattern was cemented after removing supports. The printing of individual layers of the ABS material caused unevennesses on the pattern. To remove these unevenness the pattern has to be cemented and ground. 
3 layers of cement were applied to the pattern in 5 minutes intervals. A cementing spray was used after cementing. The cement was let to dry for 24 hours after finishing. The pattern was ground after drying. Four grades of sandpaper were used for grinding, in the rage of $400-1000$. The grinding was done under water.

\section{Production of silicon mould using ABS pattern}

A silicon mould is used for a fast production of several wax patterns, where the producer ensures a certain stability of silicon mould dimensions. In this case, the stability of dimensions depends on the silicon type used, on the casting temperature, and on the chemical composition of the wax used. This precision is sufficient for the production of prototype castings, where the endurance of silicon moulds in the order of several tens of wax patterns is necessary. The accuracy falls with the growing number of patterns cast.

For the production of the silicon mould for our specific part, it was necessary to determine beforehand how the parting plane would look like, so that wax patterns could be removed from the silicon mould made easily and without failure. The mould was made from nine parts by reason of that.

The silicon of SILASTIC T-4 type from EBALTA Kunststoff Company was used for the mould production it was hardened by Silastic T-4 Curing Agent hardener. This silicon has high strength, so that it is ideal for forming in a prototype and small batch production. It was developed for the cooperation with Rapid Prototyping mainly.

Characteristic features:

- Sufficient time to remove moulds

- Hardening can be accelerated with the help of heat

- $\quad$ Silicon is of transparent colour

- Very low shrinkage and a good dimensional accuracy

- It is suitable for casting at high temperatures

Silicon is a two-component system consisting of a base component, which is made up by the very SILASTIC T-4 silicon, and the hardening component, which is made up by SILASTIC T4 Curing Agent in our case. These components are mixed in the ration of 100:10 weight parts. After a thorough mixing of both components, it is necessary to degas the silicon in order to remove air bubbles in it. Degassing is done in a degassing chamber (Fig. 4). The time of degassing is individual and depends on the silicon amount.

It is necessary to use a separator for the dismantling of individual mould parts. It is a parting medium for silicon. The workspace must be sufficiently ventilated when using it. The separator is toxic, inflammable, and irritates skin. It is usable up to the temperature of $70^{\circ} \mathrm{C}$. It is applied using a brush.

It took 24 hours to produce each mould part because of correct silicon hardening. After making a complete mould, we could start the production of wax patterns (Fig. 5).

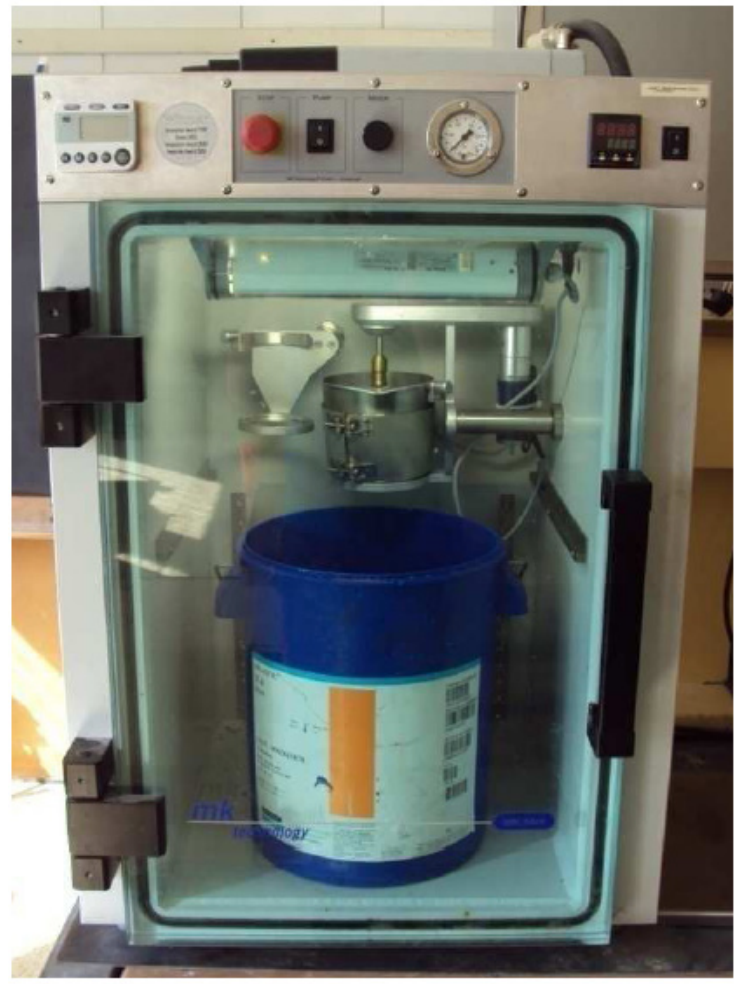

Fig. 4. MK Mini degassing chamber

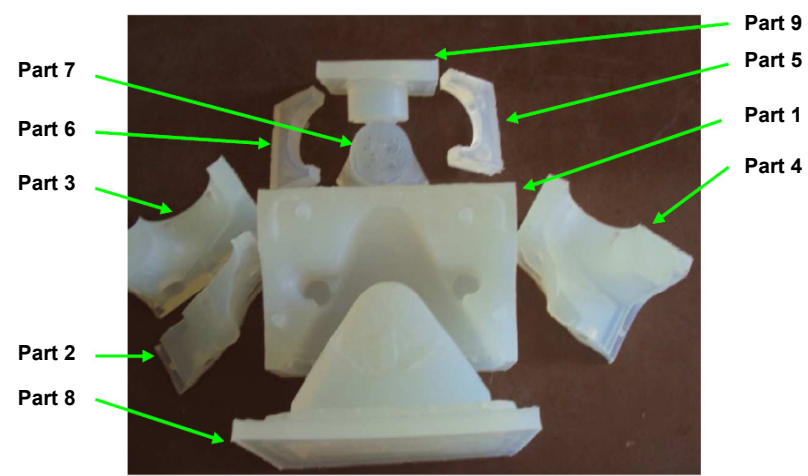

Fig. 5. Decomposed individual silicon mould parts numbered according to the production procedure

\section{E. Production of wax patterns using silicon mould}

Wax patterns were made in MCEA Systems Kuřim a.s. company, where 10 wax patterns were cast.

\section{Preparation of the silicon mould}

A gating system was made in the silicon mould before using, through which the wax was cast into the mould. The mould had to be assembled before casting and it was necessary to connect individual components together afterwards. Metal clamps were used for connecting mostly. The connection of individual components was necessary because of the buoyancy. Some 
components could get separated, and fins would occur due to that otherwise.

A silicon mould does not have a high permeability, so that it was necessary to provide the mould with vent holes in places of air accumulation to remove it.

\section{Technology of wax pattern casting}

At melting wax, the vacuum was applied to remove the redundant air in the wax. The reaction at the wax degassing was much stronger than at the silicon degassing, so that it was important to watch the wax level. It was necessary to open an air valve and to reduce thus the pressure in the chamber at the risk of wax splashing. The mould had to be pre-heated before casting. The temperature of preheating was $80{ }^{\circ} \mathrm{C}$ for the duration of 45 minutes. The mould was cast immediately after drawing out. 10 minutes of cooling in the air followed and the mould was placed to the freezing box subsequently. The mould was taken out from the box after two hours and dismantled. The wax pattern was withdrawn from the mould and small corrections of the surface were made. The total production of one wax pattern starting with the wax melting through casting, cooling, and corrections of the pattern surface lasted approximately 4 - 5 hours (characteristics of the wax mixture of Blayson company, type A7-RT/27 and casting parameters (Table 1, Table 2)).

Table 1.

Characteristics of the used wax mixture A7-RT/27

\begin{tabular}{lc}
\hline Solidification point $\left[{ }^{\circ} \mathrm{C}\right]$ & $60-64$ \\
\hline Melting point $\left[{ }^{\circ} \mathrm{C}\right]$ & $63-67$ \\
\hline Filling content $[\%]$ & $30-33$ \\
\hline Free linear shrinkage $[\%]$ & $0.6-0.8$ \\
\hline Ash content $[\%]$ & Max. 0.03 \\
\hline Viscosity [Pa.s] & $0.2-0.4$ \\
\hline
\end{tabular}

Table 2.

Parameters for casting

\begin{tabular}{lc}
\hline Temperature of mould pre-heating $\left[{ }^{\circ} \mathrm{C}\right]$ & 80 \\
\hline Temperature of wax at casting $\left[{ }^{\circ} \mathrm{C}\right]$ & 80 \\
\hline Value of wax degassing [mbar] & 20 \\
\hline Value of vacuum at casting [mbar] & 150 \\
\hline Cooling parameters [min] - air & 10 \\
\hline Cooling parameters [min] - freezer & 90 \\
\hline
\end{tabular}

\section{F. Production of castings using investment casting technology}

Two clusters by four wax patterns were made. Eight physical castings from aluminium alloy were the result.

Wax patterns produced were glued to a suitable gating system, always four wax patterns to one sprue. Patterns were fastened to the sprue by soldering. A pattern was fastened to the gating system to facilitate an easy coating and an access to all areas. In this case, wax patterns were fastened behind places, where the gating system was located at their production (Fig. 6).

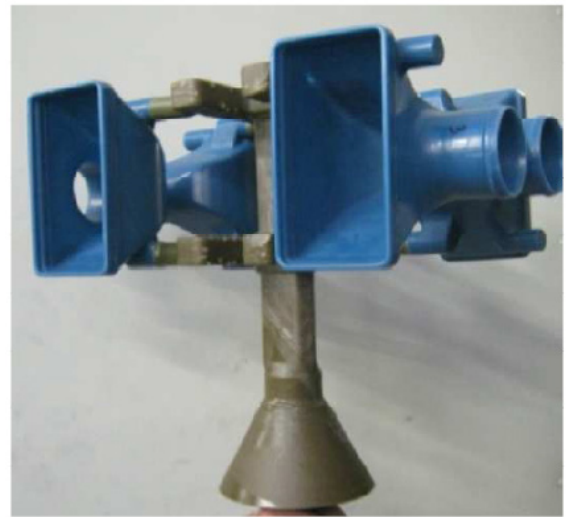

Fig. 6. Fastening patterns to a sprue into a so-called cluster

A ceramic shell was produced after making a cluster (Table 3), which was dried in the drier. The range of the time was $12-24$ hours. Melting the wax out of the shell in a boilerclave was the following step.

Table 3.

Specification for coating

\begin{tabular}{ll}
\hline Binder + Flour (slurry $1^{\text {st }}$ coat) & Primcote $+50 \%$ zircon +50 Fused silica RP1 200 mesh $)$ \\
\hline Binder + Flour (slurry $2^{\text {nd }}-5^{\text {th }}$ coats $)$ & Remasol SP Ultra + Remasil 48 RP200C \\
\hline Spray spread $\left(1^{\text {st }}\right.$ coat $)$ & Fused silica RG1 \\
\hline Fluid spread $\left(2^{\text {nd }}\right.$ coat $)$ & 150 \\
\hline Fluid spread $\left(3^{\text {rd }}-5^{\text {th }}\right.$ coats $)$ & 10 \\
\hline Temperature in the room & $23 \pm 1{ }^{\circ} \mathrm{C}$ \\
\hline Humidity in the room & $45 \pm 5^{\circ} \mathrm{C}$ \\
\hline
\end{tabular}

After removing the wax from the shell, an annealing in the electric resistance furnace at the temperature around $600{ }^{\circ} \mathrm{C}$ was done. The annealing removed the redundant water from the shell.

The metal was then cast to the shell. The annealed shell was taken out of the furnace and placed into the casting bed. The melted metal was cast to the shell in the shortest time possible after withdrawing from the annealing furnace. The shells were air cooled after casting (Table 4, Fig. 7).

Table 4.

Shell casting specification

\begin{tabular}{lc}
\hline Furnace & EN AC 21200 \\
\hline Material & EN 42 200 AlSi7Mg0.6 \\
\hline Melting temperature $\left[{ }^{\circ} \mathrm{C}\right]$ & 760 \\
\hline Casting temperature $\left[{ }^{\circ} \mathrm{C}\right]$ & 730 \\
\hline Casting time $[\mathrm{s}]$ & 5 \\
\hline
\end{tabular}




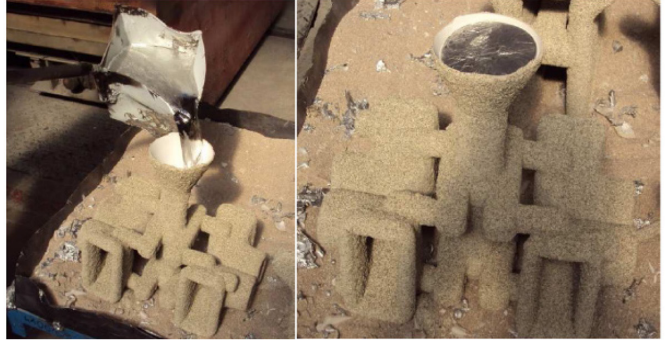

Fig. 7. Metal pouring into the shell and the subsequent cooling

The cooled shell was broken and castings were separated from the gating system (Fig. 8)
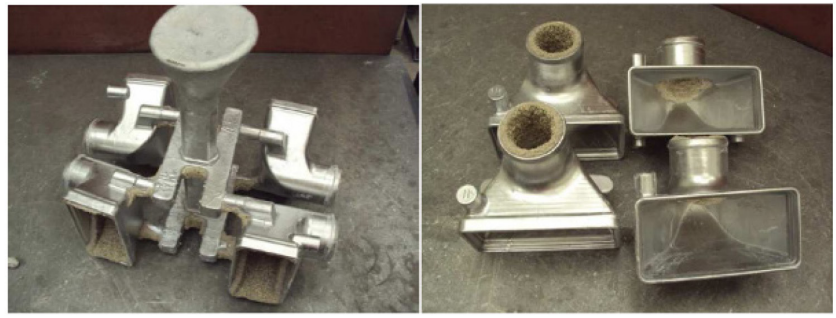

Fig. 8. The knocked out shell and castings separated from the gating system

It was necessary to remove the redundant shell from the castings separated from the gating system, which was not removed at knocking out. Castings were placed to the shot blast equipment, where the surface was sandblasted with corundum. Final castings were the result of the entire process.

\section{Methodology of measuring}

It was the objective to determine dimensional changes happening during individual stages of production. A rate of shrinkage was established from these stages.

\section{Measurements in individual stages of production}

The part was measured during the whole production. The measurement was done using a digital calliper rule.

- Measuring range $-0 \div 150 \mathrm{~mm}$

- Resolution $-0.01 \mathrm{~mm}$

- Gauge error $- \pm 0.03 \mathrm{~mm}$

5 dimensions of the part were measured - A, B, C, D and E (Fig. 9).

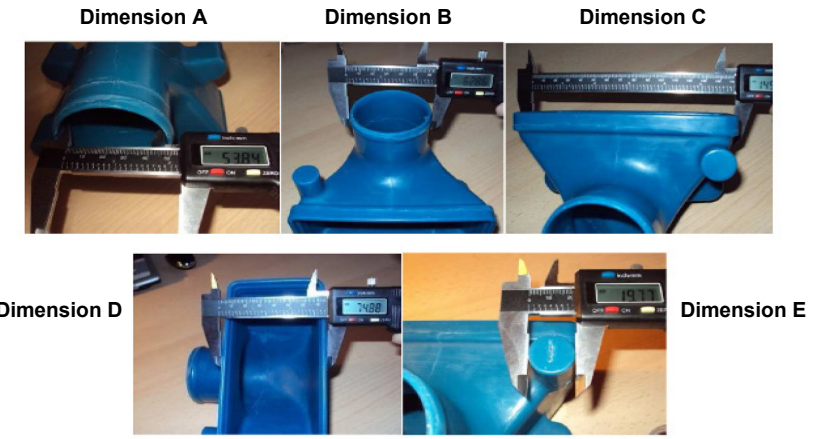

Fig. 9. Representation of measured dimensions of wax patterns

\section{Processing and evaluating measured values}

\section{A. Total change of castings dimensions as compared with the drawing documentation}

The deviation of dimensions and percentual change of dimensions were calculated in Excel. The shrinkage of the drawing dimensions (Table 5) as compared with the dimensions of the castings (Table 6, Table 7, and Table 8) is shown below.

$\Delta X=\frac{\overline{X_{\text {Výkres }}}-\overline{X_{\text {Odlitek }}}}{\overline{X_{\text {Výkres }}}} \times 100[\%]$

$\Delta \mathrm{X}$ - the shrinkage of dimensions of castings as compared with wax patterns

$\mathrm{X}_{\mathrm{výk} \text { res }}$ - the value of drawing dimensions

$\mathrm{X}_{\text {odlitek }}$ - the arithmetic mean of values of castings dimensions

Table 5.

Table of drawing dimensions

\begin{tabular}{ccc}
\hline Dimension & $\begin{array}{c}\text { Drawing } \\
{[\mathrm{mm}]}\end{array}$ & $\begin{array}{c}\text { Drawing tolerances } \\
{[\mathrm{mm}]}\end{array}$ \\
\hline $\mathrm{A}$ & 54 & -0.5 \\
\hline $\mathrm{B}$ & 63 & +0.5 \\
\hline $\mathrm{C}$ & 149.9 & \pm 0.65 \\
\hline $\mathrm{D}$ & 75.2 & \pm 0.37 \\
\hline $\mathrm{E}$ & 20 & \pm 0.5 \\
\hline
\end{tabular}

Table 6.

Measured values of castings

\begin{tabular}{ccccccccc}
\hline Casting Nr. & 1 & 2 & 4 & 4 & 5 & 6 & 7 & 8 \\
\hline Dimension A & 53.51 & 53.46 & 53.45 & 53.45 & 53.48 & 53.46 & 53.46 & 53.44 \\
\hline Dimension B & 62.40 & 62.38 & 62.35 & 62.34 & 62.34 & 62.37 & 62.36 & 62.35 \\
\hline Dimension C & 148.30 & 148.28 & 148.25 & 148.24 & 148.23 & 148.26 & 148.23 & 148.21 \\
\hline Dimension D & 74.51 & 74.55 & 74.52 & 74.55 & 74.51 & 74.54 & 74.53 & 74.52 \\
\hline Dimension E & 19.56 & 19.57 & 19.58 & 19.55 & 19.56 & 19.58 & 19.56 & 19.57 \\
\hline
\end{tabular}


Table 7.

Calculation of the arithmetic mean and the tolerance for dimensions

\begin{tabular}{ccc}
\hline Dimension & Arithmetic mean & $\begin{array}{c}\text { Dimension tolerances } \\
\text { Max-Min }\end{array}$ \\
\hline A & 53.464 & 0.07 \\
\hline B & 62.361 & 0.06 \\
\hline C & 148.25 & 0.09 \\
\hline D & 74.529 & 0.04 \\
\hline E & 19.566 & 0.03 \\
\hline
\end{tabular}

Table 8.

Changes of dimensions of castings as compared with drawing values

\begin{tabular}{ccc}
\hline Dimension & $\begin{array}{c}\text { Dimension shrinkage } \\
{[\mathrm{mm}]}\end{array}$ & $\begin{array}{c}\text { Dimension shrinkage } \\
\text { in \% }\end{array}$ \\
\hline $\mathrm{A}$ & 0.536 & 0.993055556 \\
\hline $\mathrm{B}$ & 0.639 & 1.013888889 \\
\hline $\mathrm{C}$ & 1.650 & 1.100733823 \\
\hline $\mathrm{D}$ & 0.671 & 0.892619681 \\
\hline $\mathrm{E}$ & 0.434 & 2.16875 \\
\hline
\end{tabular}

\section{B. Comparison of drawing dimensions with dimensions of castings}

Individual drawing dimensions ( $\mathrm{A}, \mathrm{B}, \mathrm{C}, \mathrm{D}$, and $\mathrm{E})$ and dimensions of castings were compared using Excel. Graph 1 shows the total change starting from drawing dimensions to the final casting.

Graph 1 demonstrates the total change of dimensions of castings as compared with drawing dimensions. This change served to determine the total change and thus the subsequent raising of the original drawing dimensions (see the example in the Figure 10).

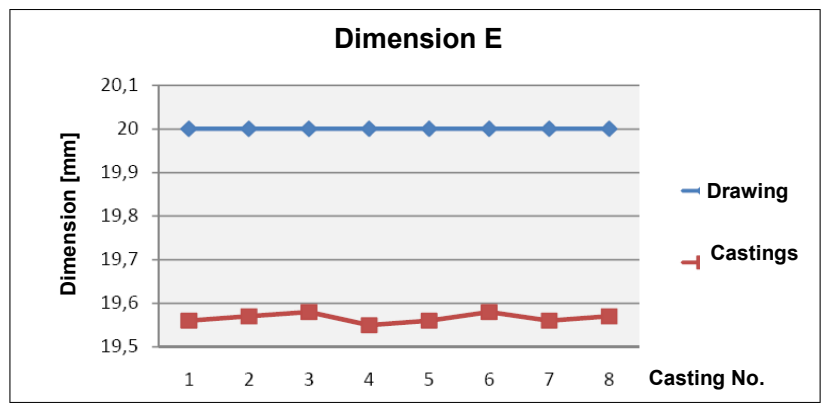

Fig. 10. Example of changes of dimensions of the casting as compared with the drawing

During production of the casting, dimensional changes took place in individual production stages. These dimensional changes were measured, recorded, and summarized in a table (Table 9) in the process of production. It is evident that the dimensions measured shrank approximately by $1 \%$; the shrinkage value of the E dimension only amounted to over $2 \%$.

A value, by which it was necessary to increase the original dimensions applied at the production, was determined from the total change of dimensions. The total value of shrinkage found was added to the original value (Table 10).

Table 9.

Table summarizing shrinkages in individual production stages

\begin{tabular}{ccccccccc}
\hline Dimension & $\begin{array}{c}\text { Deviation } \\
\text { ABS [mm] }\end{array}$ & $\begin{array}{c}\text { Change } \\
\text { ABS \% }\end{array}$ & $\begin{array}{c}\text { Wax } \\
\text { shrinkage } \\
{[\mathrm{mm}]}\end{array}$ & $\begin{array}{c}\text { Wax } \\
\text { shrinkage } \\
\text { in \% }\end{array}$ & $\begin{array}{c}\text { Casting } \\
\text { shrinkage } \\
{[\mathrm{mm}]}\end{array}$ & $\begin{array}{c}\text { Casting } \\
\text { shrinkage } \\
\text { in \% }\end{array}$ & $\begin{array}{c}\text { Total } \\
\text { shrinkage } \\
{[\mathrm{mm}]}\end{array}$ & $\begin{array}{c}\text { Total } \\
\text { shrinkage } \\
\text { in \% }\end{array}$ \\
\hline $\mathrm{A}$ & 0.09 & 0.1667 & 0.063 & 0.11686 & 0.383 & 0.71173 & 0.536 & 0.99305 \\
\hline $\mathrm{B}$ & 0.14 & 0.2222 & 0.065 & 0.10340 & 0.434 & 0.69073 & 0.639 & 1.01388 \\
\hline $\mathrm{C}$ & 0.52 & 0.3469 & 0.163 & 0.10911 & 0.967 & 0.64804 & 1.650 & 1.10073 \\
\hline $\mathrm{D}$ & 0.17 & 0.2261 & 0.208 & 0.27722 & 0.293 & 0.39193 & 0.671 & 0.89261 \\
\hline $\mathrm{E}$ & 0.09 & 0.45 & 0.153 & 0.76845 & 0.191 & 0.96548 & 0.434 & 2.16875 \\
\hline
\end{tabular}

Table 10.

Table of changes of original dimensions due to shrinkages

\begin{tabular}{ccccc} 
Dimension & $\begin{array}{c}\text { Original } \\
\text { dimension }\end{array}$ & $\begin{array}{c}\text { Total } \\
\text { shrinkage } \\
{[\mathrm{mm}]}\end{array}$ & $\begin{array}{c}\text { Total shrinkage } \\
\text { in \% }\end{array}$ & $\begin{array}{c}\text { New dimension after } \\
\text { increase by shrinkage } \\
{[\mathrm{mm}]}\end{array}$ \\
\hline $\mathrm{A}$ & 54 & 0.536 & 0.99305 & 54.6 \\
\hline $\mathrm{B}$ & 63 & 0.639 & 1.01388 & 63.7 \\
\hline $\mathrm{C}$ & 149.9 & 1.650 & 1.10073 & 151.6 \\
\hline $\mathrm{D}$ & 75.2 & 0.671 & 0.89261 & 75.9 \\
\hline $\mathrm{E}$ & 20 & 0.434 & 2.16875 & 20.5 \\
\hline
\end{tabular}

\section{Evaluating tolerances of dimensions achieved at castings}

This part aims to evaluate the stability of the production process of castings with the help of a process capability graph. This graph shows, whether a process is capable of making products in compliance with technical terms or not. Technical terms are given by certain limits, e. g. tolerance limits. It was determined then from the position on the Gaussian curve, whether final castings fulfilled the given tolerance limit or not. The process capability rate was determined using $\mathrm{Cp}$ and $\mathrm{Cpk}$ capability rates. These rates show, whether values are or are not within required limits (USL and LSL).

$\mathrm{Cp}$ - process capability index

Cpk - process variability index

USL - upper specification limit (upper limit)

LSL - lower specification limit (lower limit)

$\sigma$ - standard deviation

$\mathrm{X}$ - arithmetic mean

Process capability was determined according to $\mathrm{Cp}$ values:

- If $\mathrm{Cp}>1.33$, the process was considered to be stable,

- If $\mathrm{Cp}<1.33$ the process was considered to be unstable.

It was determined according to Cpk values, where the mean value of the process lies relative to specified USL and LSL limits. 
If $\mathrm{Cpk}<1.33$, the mean process value lies out of specified USL and LSL limits

- $\quad$ If $\mathrm{Cpk}=1.33$, the mean process value equals one of specified USL and LSL limits

- $\quad$ If $\mathrm{Cpk}>1.33$, the mean process value lies among specified USL and LSL limits

- If $\mathrm{Cpk}<1.33$, the mean process value lies out of specified limits

USL and LSL. [1], [2]

$c p=\frac{U S L-L S L}{6 \times \sigma} c p k=\min \left[\frac{U S L-X}{3 \times \sigma} ; \frac{X-L S L}{3 \times \sigma}\right]$

\section{Evaluating stability of the castings production process}

Graphs for individual castings (Fig. 11) were made using the MINITAB program. Areas below the Gaussian curve showing the location of measured dimensions are represented in individual graphs. The width indicates the extent and the height indicates the frequency of values incidence. The graph shows further tolerance limits for individual dimensions from the drawing of the part.

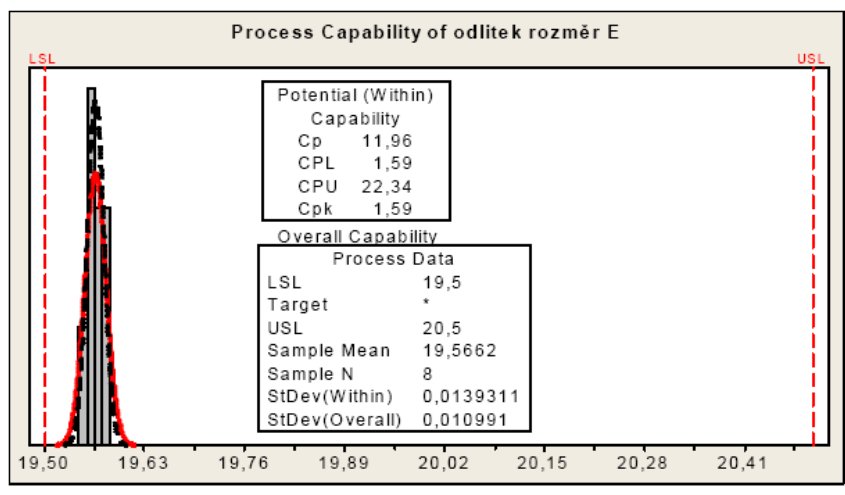

Fig. 11.. Example of reliability indices graph

It is evident from the capability indices that the $\mathrm{Cp}$ index of all measured dimensions is higher than 1.33 so that the process can be considered to be stable. At evaluating tolerances achieved by means of the Cpk index, a value higher than 1.33 was found at the Edimension only, so that it is the only one lying in the specified tolerance. On the contrary, $\mathrm{Cpk}$ index values of dimensions $\mathrm{A}$ to $\mathrm{D}$ are negative, therefore the mean process value is out of the tolerance zone given by the drawing (Table 11).

The position of values below the lower tolerance limit is caused by the shrinkage of dimensions during individual production stages. Shifting dimensions to specified tolerance limits is achieved by increasing original dimension in the drawing.
Table 11.

Table of capability indices for castings

\begin{tabular}{ccccccc}
\hline Castings & $\begin{array}{c}\text { Standard } \\
\text { deviation }\end{array}$ & $\mathrm{X}$ & USL & LSL & $\mathrm{Cp}$ & $\mathrm{Cpk}$ \\
\hline Dimension A & 0.022 & 53.465 & 54 & 53.5 & 5.06 & -0.73 \\
\hline Dimension B & 0.021 & 62.361 & 63.5 & 63 & 5.98 & -15.28 \\
\hline Dimension C & 0.0293 & 148.250 & 149.25 & 150.55 & 11.41 & -17.55 \\
\hline Dimension D & 0.0164 & 74.529 & 75.57 & 74.83 & 5.13 & -4.17 \\
\hline Dimension E & 0.0106 & 19.566 & 20.5 & 19.5 & 11.96 & 1.59 \\
\hline
\end{tabular}

\section{Comparing achieved IT grades of accuracy}

IT grades of accuracy of dimensions were specified for castings made using a silicon mould. The established IT grades of accuracy of dimensions were compared with IT grades of accuracy achieved on the test specimens. Test castings were made at the FIMES a.s. company with the help of wax patterns made in the metal mould that should have been used for the production of series castings subsequently. Individual IT grades of accuracy were specified for each dimension separately. The IT grade of accuracy was determined then from the difference of the maximum and minimum values of the dimension using engineering tables, namely the table of the ISO system of limits and fits ISO ČSN EN 20286-1.

It is evident from data in Table 12 that dimensions of castings made using a silicon mould were in the $8^{\text {th }}$ and $9^{\text {th }}$ IT grades of accuracy, while dimensions of test castings from the metal mould achieved a precision of $10^{\text {th }}$ to $12^{\text {th }}$ grades. The lower IT grade of accuracy of castings from a silicon mould could have been caused by a small number of tested values in the set; only 8 values were used namely. Higher deviations in dimensions would have occurred probably with a higher number of tested values. On the other hand, higher IT grades of accuracy of castings from the metal mould could have been caused by the fact that they were test castings only and that certain corrections of mould dimensions were done before they were used in the series production.

Table 12.

Comparing achieved IT grades of accuracy

\begin{tabular}{ccc}
\hline Castings & $\begin{array}{c}\text { IT grades of accuracy for } \\
\text { castings made using silicon } \\
\text { mould }\end{array}$ & $\begin{array}{c}\text { IT grades of accuracy } \\
\text { for castings made } \\
\text { using metal mould }\end{array}$ \\
\hline Dimension A & 9 & 10 \\
\hline Dimension B & 9 & 12 \\
\hline Dimension C & 9 & 11 \\
\hline Dimension D & 8 & 11 \\
\hline Dimension E & 8 & 10 \\
\hline
\end{tabular}

\section{Conclusion - Evaluation of results achieved}

Changes in dimension took place at the production of the ABS pattern already, where dimensions were reduced as compared with drawing values. This change could have come about because of two reasons. Firstly, a pattern of smaller dimensions than drawing 
dimensions could have been printed at the ABS pattern printing already. The second reason could have been the surface treatment of the pattern. More cement than necessary could have been taken away at the cementing and subsequent surface grinding. This fact is very difficult to monitor at the surface treatment. It should be the objective of the treatment to come as near as possible to the required dimensions.

At the production of the wax patterns, dimensional changes happen in consequence of the wax mixture shrinkage during the solidification. A shrinkage of approximately $0.1-0.2 \%$ was found at thin-walled dimensions $\mathrm{A}$ to $\mathrm{D}$, which shows that dimensions behaved almost evenly at the shrinkage. On the contrary, the percentual shrinkage of the E dimension made of a full section of a higher thickness was approximately $1 \%$. The higher percentage of the dimension shrinkage could have been caused by the dimension having a bigger thickness as compared to other dimensions. This dimension solidified for a longer time so that the shrinkage was higher. One more change of dimensions, namely lessening of dimensions during the production, takes place in the stage of wax patterns production. This change could have been caused by the gradual shrinkage of the silicon mould owing to the thermal load at a heating-up and subsequent chilling. The highest difference of shrinkages occurred in the last production stage, namely when comparing wax patterns and ready castings. The shrinkage was in the range of $0.5-0.6 \%$, whereas the shrinkage of the E dimension was the highest, it amounted to approximately $0.9 \%$. This shrinkage was caused by the shrinkage of the aluminium alloy itself, from which the castings were made. The value of the total resulting shrinkage, which took place during the entire production process starting from the specified drawing dimensions up to ready castings, was determined from all partial values. The total shrinkage of most values amounted to approximately $1 \%$; it exceeded $2 \%$ in case of the dimension $\mathrm{E}$ only. Out of the total change during the production values were determined subsequently, by which it was necessary to raise original dimensions so as to achieve drawing dimensions specified by the customer during further production with respect to the expected shrinkage.

The stability of production of the castings produced was determined. It was found that the production process was stable $(\mathrm{Cp}>1.33)$. It means that castings were produced in a very narrow range of values and could have been used thus for further processing. It was determined by means of the Cpk capability index in this test, whether measured values were in the range of tolerances given by the drawing or not. It was found that except for the $\mathrm{E}$ dimension, which conformed to limits, the $\mathrm{A}$ to $\mathrm{D}$ dimensions were out of the tolerance range. The position of the measured dimensions below the lower tolerance limit is seen in graphs above.

In the end, the IT grades of accuracy achieved at measured dimensions of castings made using a silicon mould were compared with test castings made using a metal mould. This comparison showed that dimensions of castings made using a silicon mould were in the span of $8^{\text {th }}$ and $9^{\text {th }}$ IT grades of accuracy, while castings from the metal mould were in the span of $10^{\text {th }}$ to $12^{\text {th }}$ IT grades. Castings made using a silicon mould had a very narrow span of values, which could have been caused by a low number of pieces produced, because there were only 8 of them. Worsening features of the silicon mould could have manifested themselves at a higher number of pieces and could have caused an increase of the measured values span.

\section{Acknowledgments}

The article is one of the main outputs of the TA $131 \mathrm{~S} 01000$ Project "Research and Development of Technology of Production of Sizeable, Thin-Walled, and High-Grade Castings from Al alloys" financed by the Technology Agency of the Czech Republic, to whom the main acknowledgements go. Acknowledgements belong further to employees of Fimes Uherské Hradiště, a.s. Foundry and of MCEA Systems Kuřim, a.s. company.

\section{References}

[1] Wikipedia [online] 26.10.2010 [cit.2011-09-06]. Index způsobilosti procesu. Available from WWW: $<$ https://cs.wikipedia.org/wiki/Index_zpusobilosti_procesu>.

[2] AUTOMATIZACE [online] 2004 [cit.2011-09-06]. Statistické ř́zení procesů. Available from WWW: $<$ http://www.automatizace.cz/article.php?a=228>. 